\title{
Pengaruh Pemeriksaan Kehamilan Terhadap Pemilihan Penolong Persalinan
}

\author{
Besral*
}

\begin{abstract}
Abstrak
Di Indonesia, Angka pertolongan persalinan oleh tenaga kesehatan masih tergolong rendah. Pemeriksaan kehamilan (Antenatal Care = ANC) dapat dijadikan sebagai sarana untuk memotivasi ibu hamil agar bersalin ke tenaga kesehatan. Penelitian ini bertujuan mengetahui peranan ANC terhadap pemilihan tenaga penolong persalinan. Penelitian dengan rancangan potong lintang ini menggunakan data sekunder Survei Evaluasi Manfaat Proyek KKG (Kesehatan Keluarga dan Gizi), analisisnya menggunakan ukuran asosiasi Odds Ratio. Hasil penelitian ini memperlihatkan bahwa setelah dikontrol oleh variabel karakteristik responden, ibu hamil yang melakukan ANC minimal empat kali memiliki peluang 2 kali lebih besar untuk melahirkan pada tenaga kesehatan daripada ibu hamil dengan ANC kurang dari empat kali $\left(\mathrm{OR}_{\mathrm{adj}}=2.1,95 \% \mathrm{Cl}\right.$ : $\left.1.4-3.0\right)$. Ibu hamil yang mendapat konseling berpeluang $3.7 \mathrm{kali}$ lebih besar untuk bersalin pada tenaga kesehatan daripada yang tidak mendapat konseling ( $\mathrm{OR}_{\mathrm{adj}}=3.7,95 \% \mathrm{Cl}$ : $\left.2.4-5.7\right)$. Untuk meningkatkan angka persalinan oleh tenaga kesehatan, ANC saja belumlah cukup tanpa diiringi dengan konseling. Konseling yang harus diberikan meliputi nasehat tentang kehamilan, melahirkan, dan pemberian ASI, serta anjuran yang tegas kepada ibu hamil agar melahirkan pada tenaga kesehatan.
\end{abstract}

Kata kunci:Pemeriksaan kehamilan, kualitas pemeriksaan, penolong persalinan

\begin{abstract}
Abstrak
In Indonesia, the proportion of mother who delivered by professional birth attendant is still low. The Antenatal Care (ANC) can be used to motivate mothers to have delivery assisted by health personnel birth attendant. The objective of this study is to know the role of ANC and counselling on birth delivery choice. This study used a secondary data from the Evaluation on Benefit of Family Health Nutrition (FHN) Project, which was conducted in five provinces in Indonesia. Data were analyzed using multiple logistic regressions method. The effect of ANC on birth attendant choice was measured using association measurement of odd ratio. The study showed that mothers who had four times or more ANC had 2.0 times higher chance to have delivery assisted by professional birth attendant than mothers who had less than 4 times ANC, after adjusted for mother's characteristics (family income, education and occupation of household's head), $\left(\mathrm{OR}_{\mathrm{adj}}=2.1,95 \% \mathrm{Cl}: 1.4-3.0\right)$. Mothers who got counselling were delivered by professional birth attendant 3.7 times higher than non counselled mother $\left(\mathrm{OR}_{\mathrm{adj}}=3.7,95 \% \mathrm{Cl}: 2.4-5.7\right)$. The ANC alone was not sufficient to increase the number of mother who delivered by professional birth attendant, the ANC should be complemented by counselling about pregnancy, birth attendance, breast feeding, and suggestion to have delivery assisted by professional birth attendant.
\end{abstract}

Key words: antenatal care, quality of care, professional birth attendant

*Staf Pengajar Departemen Biostatistik Fakultas Kesehatan Masyarakat Universitas Indonesia 
Persalinan yang aman dapat dicapai melalui pertolongan persalinan oleh tenaga kesehatan profesional dan ketersediaan peralatan yang memadai untuk menangani komplikasi obstetri dan neonatal. Saat ini, angka persalinan oleh tenaga kesehatan masih rendah. Hasil Survei Kesehatan Rumah Tangga (SKRT) tahun 1995 memperlihatkan bahwa proporsi pertolongan persalinan oleh tanaga kesehatan hanya 42\%,1 sedangkan SKRT tahun 2001 melaporkan pertolongan persalinan oleh tenaga kesehatan $53 \% .^{2}$ Hal tersebut mengisyaratkan tentang persalinan tenaga dukun/keluarga yang masih tinggi dan mencerminkan persalinan yang tidak aman yang dapat berdampak pada kematian ibu dan kematian bayi yang tinggi.

Salah satu upaya untuk meningkatkan persalinan yang aman adalah deteksi dini melalui pemeriksaan kehamilan yang harus dilakukan minimal 4 kali (1 kali pada trimester-1, 1 kali pada trimester-2, dan 2 kali pada trimester-3). Meskipun proporsi ibu hamil yang memeriksakan kehamilannya kepada petugas kesehatan cukup tinggi (76-78\%), ${ }^{3}$ tidak semua mereka melanjutkan pemeriksaan sesuai standar pelayanan ANC sampai dengan 4 kali, termasuk pemberian suntikan tetanus toxoid minimal 2 kali dan tablet tambah darah minimal 90 tablet. Lebih jauh lagi, tidak semua ibu hamil yang melahirkan pada tenaga kesehatan. ${ }^{4,5}$

Tenaga kesehatan perlu menyadari bahwa interaksi yang terjadi pada saat pemeriksaan antenatal merupakan momen yang penting untuk memberikan konseling yang dapat mempengaruhi ibu hamil untuk memutuskan bersalin pada tenaga kesehatan. Kesempatan itu juga dapat digunakan untuk memberikan nasehat yang berhubungan dengan kehamilan, persalinan, dan pemberian ASI.

\section{Metode}

Penelitian dengan disain penelitian cross secsional ini menggunakan sumber data sekunder proyek kesehatan keluarga dan gizi (KKG) yang dimulai pada tahun 1997 dan berakhir pada tahun 2003. Survei dilakukan oleh Fakultas Kesehatan Masyarakat - Universitas Indonesia di 7 kabupaten, di 5 propinsi lokasi proyek KKG. Pengumpulan data di setiap kabupaten dilakukan tenaga puskesmas dan dinas kesehatan yang sengaja dilatih untuk penelitian ini dan disupervisi oleh staf pengajar/peneliti dari FKM UI. Setiap kabupaten diambil sampel sebanyak 300 responden yang terdiri dari 150 responden anggota KKG dan 150 responden bukan anggota KKG. Jumlah sampel dalam sebesar inidibutuhkan untuk mendeteksi perbedaan proporsi sebesar $5 \%$ atau lebih. ${ }^{6}$ Pemilihan responden dilakukan secara acak klaster, dalam penelitian ini klasternya adalah desa. Wawancara dengan responden dilakukan menggunakan kuesioner dengan pertanyaan terstruktur yang dikem- bangkan oleh FKM UI dan telah diujicobakan di Propinsi Jambi.

Dari 2120 responden yang diwawancarai dalam survei evaluasi manfaat KKG, sebanyak 668 merupakan ibu yang pernah melahirkan dalam kurun waktu 3 tahun terakhir. Mereka inilah yang merupakan unit analisis (sampel) dari penelitan ini yang bertujuan untuk mengidentifikasi pengaruh pemeriksaan kehamilan terhadap pemilihan pertolongan persalinan. Pemilihan waktu 3 tahun terakhir berdasarkan pada asumsi bahwa si ibu masih dapat mengingat kejadian (paling lama) 3 tahun yang lalu, disamping itu proyek KKG juga telah berlangsung selama 4 tahun sebelum survei.

Analisis data dilakukan dengan menggunakan regresi logistik ganda. Perhitungan Odds Ratio (OR) dilakukan dengan mengontrol beberapa variabel karakteristik responden yang bermakna secara statistik $(p \text {-value }<0.05)^{7}$ dan dicurigai mengganggu hubungan antara pemeriksaan kehamilan dengan penolong persalinan, pembuatan model dilakukan secara bertahap dengan metode backward. 8,9

\section{Hasil}

Responden yang pernah hamil dalam periode 3 tahun terakhir adalah 668 orang, sebanyak $62.3 \%$ persalinan mereka ditolong oleh tenaga kesehatan seperti bidan atau dokter. Responden yang melakukan pemeriksaan kehamilan pada tenaga kesehatan minimal empat kali adalah $52.1 \%$. Responden yang menyatakan pernah mendapat nasihat atau konseling tentang kehamilan, persalinan, dan ASI dari tenaga kesehatan adalah $83.1 \%$. Anjuran untuk melahirkan dengan tenaga kesehatan diterima oleh $72.5 \%$ responden. Sebagian besar keluarga responden berpenghasilan Rp 250.000 - Rp 499.000 per bulan (37.8\%), berpendidikan SD atau lebih rendah $(57.6 \%)$ dan bekerja sebagai petani $(76.8 \%)$, sekitar satu dari empat responden mempunyai kartu sehat $(27.7 \%)$. Hasil analisa bivariat memperlihatkan bahwa dari 12 variabel ada 2 variabel yang tidak berhubungan yaitu kepemilikan kartu sehat (p-value 0.257) dan keanggotaan KKG (p-value 0.065).

Analisa multivariat dengan regresi logistik ganda memperlihatkan enam variabel berpengaruh bersamasama secara bermakna terhadap pemilihan penolong persalinan. Variabel tersebut meliputi pemeriksaan kehamilan, konseling dan pemberian nasehat, anjuran untuk melahirkan pada tenaga kesehatan, pendapatan keluarga, pendidikan dan pekerjaan kepala rumah tangga (Tabel 2). Keenam variabel tersebut dapat menjelaskan $74 \%$ variasi pada variabel penolong persalinan, sedangkan $26 \%$ lagi dijelaskan oleh variabel lain yang tidak diteliti. ${ }^{0,11}$

Setelah dikontrol oleh variabel karakteristik responden (pendapatan keluarga, pendidikan kepala rumah 
Tabel 1. Analisis Bivariat, Faktor-faktor yang Berhubungan dengan Pertolongan Persalinan oleh Tenaga Kesehatan

\begin{tabular}{|c|c|c|c|}
\hline \multirow[t]{2}{*}{ Variabel } & \multirow{2}{*}{$\begin{array}{c}\text { Persalinan } \\
\text { Bukan nakes }\end{array}$} & \multirow{2}{*}{$\frac{\text { n }(\%)}{\text { Nakes }}$} & \multirow[t]{2}{*}{ p-value } \\
\hline & & & \\
\hline \multicolumn{4}{|l|}{ Periksa antenatal } \\
\hline$<4$ kali & $164(51.3)$ & $156(48.8)$ & 0.000 \\
\hline \multicolumn{4}{|c|}{ Nasehat ttg hamil, bersalin, dan ASI } \\
\hline Tidak & $78(69.0)$ & $35(31.0)$ & 0.000 \\
\hline \multicolumn{4}{|l|}{ Anjuran bersalin dengan nakes } \\
\hline Tidak & $121(65.8)$ & $63(34.2)$ & 0.000 \\
\hline \multicolumn{4}{|l|}{ Pendapatan keluarga } \\
\hline Rp250-499 ribu/bulan & $66(27.5)$ & $174(72.5)$ & 0.000 \\
\hline Lebih Rp500 ribu/bulan & $69(32.5)$ & $143(67.5)$ & 0.000 \\
\hline \multicolumn{4}{|l|}{ Pendidikan kepala keluarga } \\
\hline Tamat SMP & $44(28.0)$ & $113(72.0)$ & 0.000 \\
\hline Tamat SMA atau lebih tinggi & $32(25.4)$ & $94(74.6)$ & 0.000 \\
\hline \multicolumn{4}{|l|}{ Pekerjaan kepala rumah tangga } \\
\hline Tani & $199(38.8)$ & $314(61.2)$ & 0.002 \\
\hline Dagang/Jasa/PNS/Swasta & 35 (26.9) & $95(73.1)$ & 0.000 \\
\hline \multicolumn{4}{|l|}{ Anggota KKG } \\
\hline Tidak & $145(40.7)$ & $211(59.3)$ & 0.065 \\
\hline \multicolumn{4}{|l|}{ Punya kartu sehat } \\
\hline Tidak & $186(38.6)$ & $296(61.4)$ & 0.257 \\
\hline \multicolumn{4}{|c|}{ Dikunjungi oleh tenaga kesehatan } \\
\hline Tidak & $139(47.8)$ & $152(52.2)$ & 0.000 \\
\hline
\end{tabular}

Tabel 2. Faktor-faktor yang Berhubungan dengan Pertolongan Persalinan oleh Tenaga Kesehatan (Hasil Analisis Regresi Logistik Multivariat)

\begin{tabular}{lcccc}
\hline Variabel & B & SE & p-value & OR (95\% CI) \\
\hline Periksa hamil ke nakes minimal 4 kali & 0.742 & 0.193 & 0.000 & $2.1(1.4-3.0)$ \\
Dinasehati tentang hamil, bersalin, \& ASI & 0.755 & 0.269 & 0.005 & $2.1(1.2-3.6)$ \\
Dianjurkan untuk bersalin dg nakes & 1.313 & 0.223 & 0.000 & $3.7(2.4-5.7)$ \\
Pendapatan keluarga (kurang Rp250 ribu/bl*) & & & & \\
Rp250_499 ribu/bl & 0.962 & 0.236 & 0.000 & $2.6(1.6-4.1)$ \\
Lebih Rp500 ribu/bl & 0.581 & 0.249 & 0.020 & $1.8(1.1-2.9)$ \\
Pendidikan kepala RT (Tamat SD/lebih rendah*) & & & & $1.7(1.0-2.7)$ \\
Tamat SLTP & 0.527 & 0.244 & 0.031 & $1.6(0.9-2.7)$ \\
Tamat SLTA atau lebih tinggi & 0.477 & 0.264 & 0.070 & $3.7(1.3-10.9)$ \\
Pekerjaan kepala RT (Tidak bekerja*) & & & & 0.016 \\
Tani & 1.319 & 0.547 & 0.003 & $5.6(1.8-17.8)$ \\
Dagang/Jasa/PNS & 1.730 & 0.587 & & \\
\hline
\end{tabular}

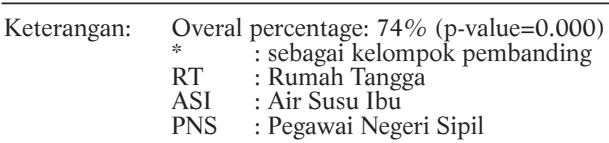

tangga, dan pekerjaan kepala rumah tangga), terlihat bahwa ibu hamil dengan ANC minimal empat kali berpeluang 2 kali lebih besar untuk melahirkan pada tenaga kesehatan $\left(\mathrm{OR}_{\mathrm{adj}}=2.1\right.$, 95\% CI: $\left.1.4-3.0\right)$ daripada ibu hamil dengan ANC kurang dari empat kali. Ibu hamil yang mendapat konseling tentang kehamilan, persalinan, dan pemberian ASI dari tenaga kesehatan berpeluang 2 kali lebih besar untuk melahirkan pada tenaga kesehatan $\left(\mathrm{OR}_{\mathrm{adj}}=2.1,95 \% \mathrm{CI}\right.$ : $\left.1.2-3.6\right)$ dari pada ibu hamil yang tidak mendapatkan konseling. Selanjutnya, ibu hamil yang secara tegas dianjurkan untuk melahirkan pada tenaga kesehatan berpeluang 3.7 kali lebih besar untuk melahirkan pada tenaga kesehatan
$\left(\mathrm{OR}_{\mathrm{adj}}=3.7\right.$, 95\%CI: 2.4-5.7) daripada ibu hamil yang tidak mendapat anjuran tersebut.

Variabel karakteristik keluarga yang berperan dalam memprediksi pemilihan tenaga kesehatan sebagai penolong persalinan adalah pendapatan keluarga (cukup), pendidikan kepala rumah tangga (minimal SLTP), dan pekerjaan kepala keluarga (pekerjaan tetap) (p-value kurang dari 0.01). Responden dengan penghasilan Rp250.000 - Rp 499.000 per bulan berpeluang melahirkan pada tenaga kesehatan 2.5 kali lebih besar daripada mereka yang berpenghasilan kurang dari Rp250.000 per bulan. Responden dengan kepala keluarganya tamat SLTP berpeluang melahirkan pada tenaga 
kesehatan 1,8 kali lebih besar daripada yang tamat SD atau lebih rendah $\left(\mathrm{OR}_{\mathrm{adj}}=1.8\right.$, 95\%CI: 1.1-2.9) (Lihat Tabel 2).

\section{Pembahasan}

Keterbatasan dalam penelitian ini adalah bahwa model hubungan antara pemeriksaan ANC dengan penolong persalinan pada tenaga kesehatan tidak dapat sepenuhnya diartikan sebagai hubungan sebab akibat, karena disain penelitian ini adalah potong lintang. Namun demikian, setidaknya pada 3 variabel utama yaitu pemeriksaan kehamilan, pemberian nasehat tentang kehamilan dan ASI, dan anjuran untuk bersalin dengan tenaga kesehatan dapat pastikan variabel ini diberikan sebelum peristiwa persalinan terjadi. Sehingga dapat saja diartikan sebagai hubungan kausal.

Angka persalinan tenaga kesehatan pada penelitian ini adalah $63 \%$, yang ternyata lebih tinggi dari hasil Survei Kesehatan Rumah Tangga tahun 2001 yang hanya sebesar 52,1\%. Sedangkan angka pemeriksaan kehamilan hampir sama dengan hasil Survei Kesehatan Rumah Tangga tahun 2001 yaitu 53\% ibu hamil memeriksakan kehamilannya sebanyak 4 kali atau lebih. Terlihat bahwa ANC sangat berperan dalam menentukan penolong persalinan, ibu hamil dengan ANC yang lengkap dan adekuat cenderung untuk bersalin dengan tenaga kesehatan. Disamping ANC, faktor lain yang juga berperan dalam pemilihan penolong persalinan adalah sosial ekonomi keluarga. Semakin baik sosial ekonomi keluarga maka tenaga kesehatan cenderung dipilih sebagai penolong persalinannya.

Penelitian ini hanya melakukan analisa terhadap variabel yang ada pada survei evaluasi manfaat proyek $\mathrm{KKG}$, sehingga keberadaan variabel lain yang berpengaruh terhadap persalinan dengan tenaga kesehatan tidak dapat dianalisa, misalnya akses terhadap tenaga kesehatan (jarak, transportasi, \& biaya). Meskipun, keenam variabel yang berhubungan secara bermakna, terbukti telah dapat menjelaskan $74 \%$ variasi pada variabel pertolongan persalinan. Hal tersebut berarti bahwa proporsi yang dapat dijelaskan cukup besar. Peran variabel lain yang tidak diteliti untuk menjelaskan hubungan tersebut hanya sebesar $26 \% .{ }^{12}$

Hubungan yang tidak bermakna didapatkan antara keanggotaan KKG dan kepemilikan kartu sehat dengan persalinan pada tenaga kesehatan, walaupun dalam analisa bivariat sekalipun, hal ini mengindikasikan bahwa proyek KKG telah berhasil menyamakan akses masyarakat terhadap pelayanan persalinan tenaga kesehatan. ${ }^{13}$ Baik anggota KKG atau bukan, punya kartu sehat atau tidak tidak, semuanya punya akses yang sama terhadap persalinan oleh tenaga kesehatan. Karena persalinan tidak termasuk dalam pelayanan kartu sehat dan umumnya anggota KKG ataupun pemilik kartu sehat be- rasal dari sosial ekonomi rendah.

Dari 3 variabel utama (pemeriksaan antenatal, konseling berupa nasehat persalinan dan ASI, dan konseling berupa anjuran bersalin dengan tenaga kesehatan), variabel yang paling besar pengaruhnya terhadap angka persalinan dengan tenaga kesehatan adalah anjuran untuk bersalin dengan tenaga kesehatan $\left(\mathrm{OR}_{\mathrm{adj}}=3.7\right)$. Sehingga, departemen kesehatan diharapkan untuk membuat kebijakan agar petugas kesehatan selalu memberikan konseling berupa nasehat tentang kehamilannya, persalinan, dan pemberian ASI, serta anjuran pada ibu hamil agar nantinya melahirkan dengan tenaga kesehatan terlatih. Penelitian ini mendapatkan hasil yang sama dengan penelitian lainnya tentang peranan pemeriksaan kehamilan terhadap pemilihan penolong persalinan, artinya semakin baik kuantitas dan kualitas pelayanan pemeriksaan kehamilan maka semakin cenderung ibu hamil tersebut untuk bersalin dengan tenaga kesehatan. ${ }^{14,15}$

\section{Kesimpulan}

1. Penelitian ini memperlihatkan hubungan yang erat ANC dengan pemilihan penolong persalinan. Ibu yang melakukan pemeriksaan ANC 4 kali atau lebih berpeluang lebih besar untuk melahirkan dengan tenaga kesehatan.

2. Peningkatan angka persalinan tenaga kesehatan tidak dapat hanya mengandalkan ANC minimal empat kali, tetapi harus diikuti dengan peningkatan kualitas ANC dan konseling.

3. Konseling meliputi materi tentang kehamilan, persalinan, pemberian ASI, dan anjuran secara tegas pada ibu hamil agar melahirkan pada tenaga kesehatan.

4. Proyek KKG tampaknya berhasil meningkatkan akses ibu hamil pada fasilitas pelayanan kesehatan. Hal ini terlihat dari tidak adanya hubungan yang bermakna antara keanggotaan KKG dan kepemilikan kartu sehat dengan pemilihan penolong persalinan.

\section{Saran}

1. Untuk meningkatkan angka persalinan oleh tenaga kesehatan di sarankan kepada petugas kesehatan untuk meningkatkan angka ANC.

2. ANC minimal 4 kali saja belum cukup, petugas kesehatan harus memberikan ANC dengan kualitas yang baik, termasuk memberikan konseling atau nasihat tentang kehamilan, melahirkan \& pemberian ASI, serta anjuran yang tegas kepada ibu hamil agar bersalin dengan petugas kesehatan.

\section{Daftar Pustaka}

1. Depkes. Laporan survei kesehatan rumah tangga 1995. Jakarta: Depkes; 1997.

2. Depkes. Laporan survei kesehatan rumah tangga 2001: Studi kesehatan ibu dan anak. Jakarta: Depkes; 2002.

3. BPS, BKKBN, Depkes, \& Macro International Inc. Survei demografi dan 
kesehatan Indonesia 1997. Jakarta: BPS;1998.

4. Badan Pusat Statistik. Statistik kesejahteraan rakyat 2000. Jakarta: BPS; 2001.

5. Depkes. Laporan data susenas 2001: status kesehatan, pelayanan kesehatan, prilaku hidup sehat, dan kesehatan lingkungan. Jakarta: Depkes; 2002.

6. Lemeshow. Sample size for health sciences. Geneva: WHO; 1998.

7. Afifi, AA. Computer-aided multivariate analysis. New York: Van Nostrand Reinhold Company; 1984.

8. Hosmer dan Lemeshow. Applied logistic regression. $2^{\text {nd }}$ eds. New York: John Willey and Sons; 2000.

9. Kleinbaum, DG. Logistic regression: a self-learning text. New York: Springe; 1998.

10. Kleinbaum DG, Kupper LL, dan Muller KE. Applied regression analy- sis and other multivariable methods. $2^{\text {nd }}$ Edition. Boston: PWS-KENT Publishing Company; 1990.

11. Kleinbaum, DG., Kupper, LL., and Morgenstern,. H. Epidemiologic research: principles and quantitave methods. New York: Van Nostrand Reinhold Publishers; 1982.

12. Netter J, Wasserman W, dan Kutner MH. Applied liner regression models. $2^{\text {nd }}$ Edition. Ilinois: Irwin Inc; 1989.

13. Rothman, KJ, dan Greenland, S. Modern epidemiology. $2^{\text {nd }}$ edition. Philadelphia: Lippincott-Raven Publishers; 1998.

14. Simanjuntak T. Faktor-faktor yang berhubungan dengan kunjungan antenatal di kota Medan. [Tesis]. Depok: Fakultas Kesehatan Masyarakat Universitas Indonesia; 2002.

15. Nurti T. Kualitas pelayanan antenatal pada puskesmas di kota Jambi. Tesis FKMUI Depok; 2002. 